\title{
Theory and Application of Rock Burst Prevention Based on Rigid-flexible Integrated Support with Energy Absorbing
}

\author{
Shan-Kun ZHAO ${ }^{1, a}$, Zhen-Hua OUYANG ${ }^{2, b, *}$, Xiao-Lu LI ${ }^{2, c}$ \\ ${ }^{1}$ School of Mechanics and Civil Engineering, China University of Mining \& Technology (Beijing), \\ Beijing 100083,China \\ ${ }^{2}$ Mine Safety Technology Branch of CCRI, 100013, China \\ ahhaoshankunco@163.com \\ ${ }^{*}$ Corresponding author
}

Keywords: Rock Burst, Rigid-flexible Integrated Support, Energy Absorbing.

\begin{abstract}
Based on the theory of stress control for rock burst prevention, rigid-flexible integrated support with energy absorbing was found. In this paper, we tested between flexible yield support and rigid-flexible integrated support with energy absorbing. The results showed that the frequency of rock burst occurrence and the intensity were both declined. The extent of damage to roadway, machines and workers were effectively avoid in several seriously rock bursts with high energy released in Yuejin coal mine, consequently, no casualties and no effect produce occurred when rock burst happened.
\end{abstract}

\section{Introduction}

With the technology development and mining intensity increasing, shallow coal resource is nearly exhausted and transfers to deep imperatively. Complex geology and stress environment cause many types of dynamic disaster during deep coal seam mining, especially the rock burst. By the end of 2012, China had more than 142 mines experiencing rock burst and caused a huge economic loss and casualties, which is seriously threat to the safety of coal mine production and miner's life. With the stress or energy released, the evolution of rock burst has a close relationship with roadway surrounding rock failure, therefore, the research on supporting technology of rock burst roadway becomes the key issue for coal mining safety.

During the last few years, many scholars from home and abroad had paid attention to the roadway supporting in rock burst and gained lots of achievements. The structural mechanics model of rigidflexible-rigid was set up and the stress/energy criterion of roadway surrounding rock failure under the impact dynamic load was made(Gao et al.,2009). The bolt-mesh-anchor support pattern and their parameters for rock burst roadway were given by study on the deformation characteristics of roadway in deep and the secondary supporting theory(Feng, et al.,2001). According to the coal roadway failure mechanism analysis, the anchor support mechanism in coal roadway was researched and the form of support was tested in practical(Chen, et al.,2000). Analysis of the mechanism of impact energy absorbed by the coupling support, an model of energy-absorbing coupling support (surrounding rock-energy absorbing material - steel bracket) was built(Pan, et al.,2011 and Zhao, et al.,2010). The research on supporting technology of rock burst roadway has made progress, but the study and practical usage on the technology of rigid-flexible integrated support with energy absorbing was seldom.

\section{Failure Mechanism of Rock Burst Roadway}

As a type of structural damage, the rock burst is a procedure transferring from stable stage to unstable stage and finally into a relatively stable stage under the mine-induced stress. During this process, the main energy was consumed in the destruction of coal and rock mass, crushing and energy transmission, the residual energy acted on the roadway surrounding rock and its supporting structure. Thus it can be seen that whether the rock burst happened and how much the energy released depend on the energy storage in coal and rock and their strength. When the strength of coal and rock can bear the load of reservoir energy, the coal rock structure remained in a equilibrium state. If the load was greater than the coal and rock structure resistance and the rock burst happened. 


\section{Technology of Rigid-flexible Integrated Support with Energy Absorbing}

\section{Thought of Rock Burst Prevention}

According to the rock burst occurring principle, the high energy stress wave around the roadway was the key factor. When the impacted hanging roof reached in a certain length, it suddenly broke on the mining workface and the shock wave produced. Because of the heterogeneity and the rock defection, the stress wave was weakened during the process of transferring. Though the rock layer interface can reflect partial energy of the incident stress wave, much of them can act on the surrounding way, which give rise to induce the rock burst happen when the support strength waken. Hence, if the high energy stress wave can waken during the transferring by the method of man-made increasing the heterogeneity of rock. The residual energy loaded on support system will be reduced. Furthermore, according to the increase of strength support, the energy of stress wave can be further reduced. The rigid-flexible integrated support with energy absorbing was put forward based on this idea, as shown in Figure 1.

In practice, the rock burst prevention support system of rigid-flexible integrated support with energy absorbing including bolt-mesh-anchor support system, energy absorption material, O-shed composed of U-shaped steel and the rigid support, as shown in Figure 2.

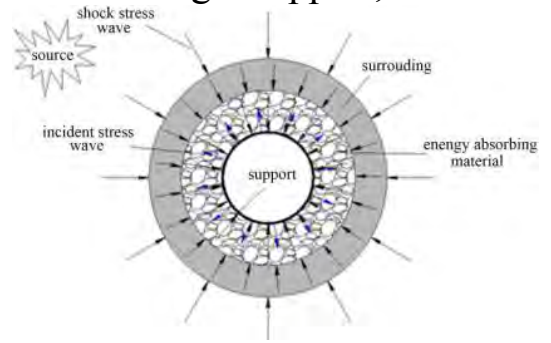

Fig. 1 The Idea of Rigid-flexible Integrated Support with Energy Absorbing

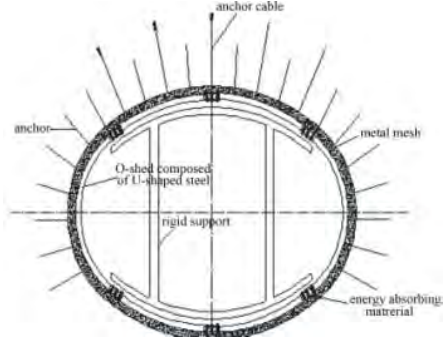

Fig. 2 The System Framework of Rigid-flexible Integrated Support with Energy Absorbing

The thought of this technology for rock burst prevention includes following several aspects. First, bolt-mesh-anchor support system was built timely and made fully used of the support resistance to change the stress state of surrounding roadway after the roadway excavation, which translates the biaxial stress into triaxial stress state and the strength and the ability of resist deformation are both improved. Second, a closed system framework based on the O-shed composed of U-shaped steel was produced after the bolt-mesh-anchor support system set up. Because O-shed composed of U-shaped steel has better scalability and allows some displacements among hinges under the impact loading, which can alleviate the impact energy act on the supporting structure directly and has the effect of flexible yield. Furthermore, this support system is able to control the floor heave of roadway and the deformation roadway's sides effectively during the rock burst occurring. Third, a large number of impact energy was absorbed by adding an layer of absorption material between the bolt-mesh-anchor support system and the O-shed composed of U-shaped steel, which will reduced the impact energy destroyed the supporting structure. At last, a larger stiffness steel support was built between two $\mathrm{O}$-shed. The purpose of is not only absorbing the last surplus impact energy, but also increasing the overall stability of the rigid-flexible integrated support with energy absorbing.

\section{Numerical Simulation Analysis}

In order to verify the effectiveness of rigid-flexible integrated support with energy absorbing for rock burst control, two different support forms of flexible yield support and rigid-flexible integrated support with energy absorbing support for surrounding stability were studied with FLAC3D simulation software. The simulate prototype was 25110 workface roadway in Yuejin coal mine, which is located in Henan province. The mechanical parameters of coal and rock for the simulation were all tested in laboratory and in-situ stress were measured with hydraulic fracturing method. The model is as shown in Figure 3 . The model was set as 24 meters in length, 24 meters in height and 4 meters in width. Displacement boundaries was set on the bottom of the model and the stress boundary were set on other directions, the $\mathrm{X}, \mathrm{Y}, \mathrm{Z}$ three directions of stress condition were: $\sigma \mathrm{x}=9.1 \mathrm{MPa}, \sigma \mathrm{y}=17.1 \mathrm{MPa}, \sigma \mathrm{z}=22.6 \mathrm{MPa}$. 


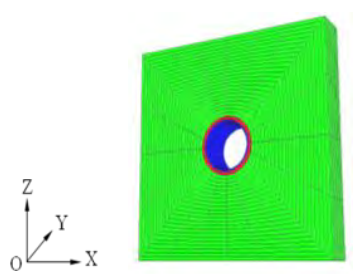

Fig. 3 The Model of Numerical Simulation of Rigid-flexible Integrated Support with Energy Absorbing

Flexible Yield Support. A roadway with inner diameter $\mathrm{r} 12.8 \mathrm{~m}$ was excavated in the middle of model. The length of the roof anchor was $2.2 \mathrm{~m}$ with the spacing $0.8 \mathrm{~m}$ and the distance between two rows was $0.8 \mathrm{~m}$. The anchor cable were installed with the same parameter where the length was $8 \mathrm{~m}$, the spacing was $1.5 \mathrm{~m}$ and the distance between rows was $0.8 \mathrm{~m}$. On both sides of the roadway, the length of the anchor was $1.8 \mathrm{~m}$, the spacing was $0.8 \mathrm{~m}$ and the distance two rows was $0.8 \mathrm{~m}$. When the anchor and the cable were installed, the $\mathrm{O}$-shed were set up in $\mathrm{Y}$ - distraction along the roadway at $\mathrm{y}=1.6, \mathrm{y}=2.4, \mathrm{y}=3.2$ and $\mathrm{y}=4.0$ respectively.

Rigid-flexible Integrated Support with Energy Absorbing. The roadway was excavated with radius $\mathrm{r} 2=2.8 \mathrm{~m}$ in the middle of the model and the parameters of the anchor and cable as same as the flexible yield support. After they were installed, the loose energy absorption material was in filled within the scope of $2.8 \mathrm{~m}-3.6 \mathrm{~m}$ in radial direction. At last, the O-shed with $0.2 \mathrm{~m}$ thick and $0.2 \mathrm{~m}$ length was installed along the roadway in $Y$-direction at $\mathrm{y}=0, \mathrm{y}=0.8, \mathrm{y}=1.6, \mathrm{y}=2.4, \mathrm{y}=3.2$ and $\mathrm{y}=4.0$, the rigid support was installed at $\mathrm{y}=0, \mathrm{y}=2.0$ and $\mathrm{y}=4.0$.

The failure criterion is the Mohr-Coulomb, the physical and mechanical parameters of energy absorption materials and surrounding rock are determined according to project experience and the results of indoor test reduction, as shown in Table 1. There was no loose energy absorption material in flexible yield and the parameters of roadway surrounding in model were valued according to mechanical test.

Tab. 1 The Physical and Mechanical Parameters of Numerical Modeling

\begin{tabular}{|c|c|c|c|c|c|}
\hline Material & $\begin{array}{l}E \\
(\mathrm{GPa})\end{array}$ & $\mu$ & $\begin{array}{l}C \\
(\mathrm{MPa})\end{array}$ & $\varphi\left(^{\circ}\right)$ & $\begin{array}{l}\gamma \\
\left(\mathrm{kN} / \mathrm{m}^{3}\right)\end{array}$ \\
\hline Loose rock & 1.20 & 0.08 & 0 & 30 & 1350 \\
\hline Rock/coal & 4.28 & 0.21 & 7.16 & 30.4 & 1368.75 \\
\hline
\end{tabular}

Fig. 4 The Time History Curve of Shock Load.

Furthermore, as a structure failure under high stress, rock burst was not only related with the in-situ stress, but also influenced by the mining induced stress. As a dynamic change stress, mining induced stress contains the static stress and dynamic stress. In practice, rock burst always happen before the workface, where the whole structure states in relatively balance and the static stress nearly to the maximum, when a little dynamic load would induce its loss of stability. The dynamic stress was usually caused by blasting and roof fracture and traveled in a form of stress waves. This kind of stress waves was mainly longitudinal wave which transfers into compressive stress, it's the load source for structure protective in geotechnical.

In the model of FLAC3D dynamic calculation, the absorbing boundary conditions was used to simulate the infinite space and placed a triangle impact load on the left, which lasted $0.005 \mathrm{~s}$ and then reached the maximum load $50 \mathrm{MPa}$ at $0.0025 \mathrm{~s}$, the load-time history curve as shown in Figure 4.

\section{Numerical Simulation Result}

The protective effect is a significantly different from the flexible yield support to rigid-flexible integrated support with energy absorbing under the same impact load. The test results of stress in Figure 5(a) and energy in Figure 5(b) of the numerical simulation at different location were shown in Table 2. 

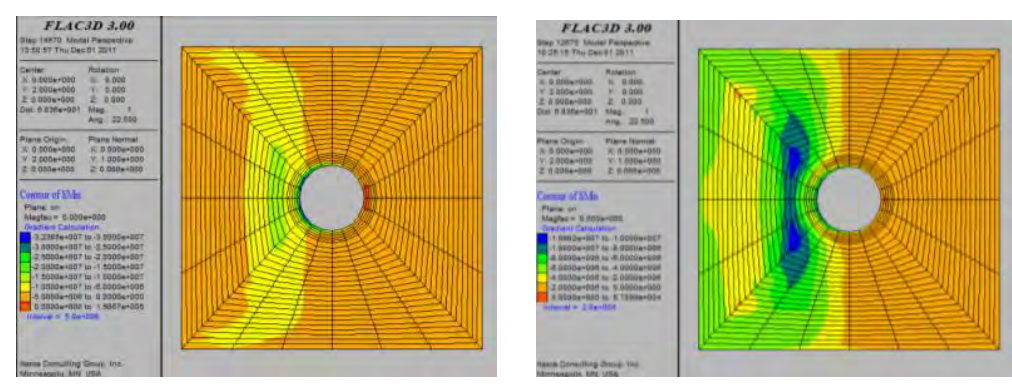

(a) Comparison of Maximum Principal Stress Nephogram
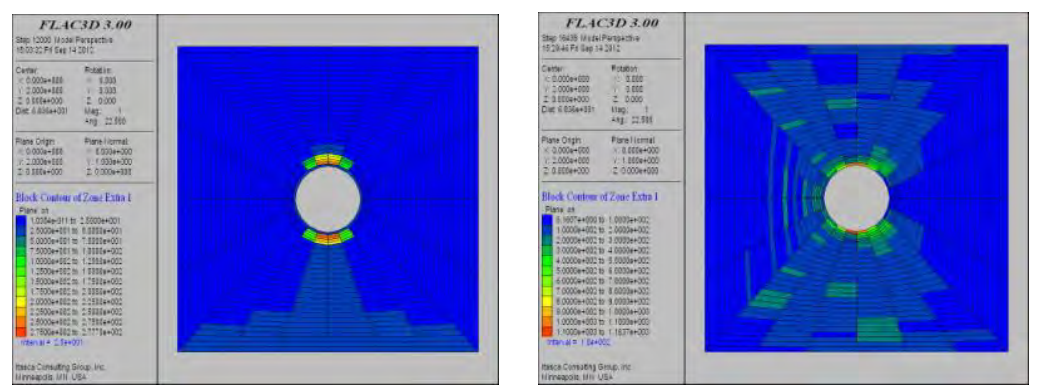

(b) Comparison of Energy Field around Roadway Surrounding

Fig. 5 Prevention Effect Comparison between Flexible Yield Support and Rigid-Flexible Integrated Support with Energy Absorbing under the Same Impact Load

Tab. 2 The Stress and Energy Change under Different Support Form at Different Location

\begin{tabular}{|c|c|c|c|c|c|c|c|c|c|}
\hline \multirow[b]{2}{*}{ No. } & \multicolumn{4}{|c|}{ Coordinate value } & \multicolumn{2}{|l|}{ Stress/MPa } & \multicolumn{2}{|c|}{ Energy $/ \mathrm{kJ} * \mathrm{~m}-3$} & \\
\hline & $\mathrm{X}$ & $\mathrm{Y}$ & $\mathrm{Z}$ & $\begin{array}{l}\text { Flexible } \\
\text { yield } \\
\text { support }\end{array}$ & $\begin{array}{l}\text { Rigid-flexib } \\
\text { integrated } \\
\text { support wit } \\
\text { energy } \\
\text { absorbing } \\
\end{array}$ & $\begin{array}{l}\text { ble } \\
\text { Decreasing } \\
\text { vithamplitude } \\
\text { (\%) }\end{array}$ & $\begin{array}{l}\quad \text { Flexible } \\
\text { yield } \\
\text { support }\end{array}$ & $\begin{array}{l}\text { Rigid-flexible } \\
\text { integrated } \\
\text { support witl } \\
\text { energy } \\
\text { absorbing }\end{array}$ & $\begin{array}{l}\text { e } \\
\text { Decreasing } \\
\text { thamplitude } \\
(\%)\end{array}$ \\
\hline 1 & 14.80 & 2.00 & 12.00 & 4.58 & 1.53 & 66.56 & 70.54 & 28.20 & 60.02 \\
\hline 2 & 13.98 & 2.00 & 13.98 & 7.46 & 4.68 & 37.22 & 192.69 & 42.49 & 77.95 \\
\hline 3 & 12.00 & 2.00 & 14.00 & 18.58 & 5.34 & 71.26 & 1090.09 & 37.26 & 96.58 \\
\hline 4 & 10.02 & 2.00 & 13.98 & 8.45 & 7.43 & 12.08 & 240.65 & 42.44 & 82.36 \\
\hline 5 & 9.20 & 2.00 & 12.00 & 5.59 & 3.60 & 35.52 & 120.92 & 28.44 & 76.48 \\
\hline 6 & 10.02 & 2.00 & 10.02 & 9.20 & 7.52 & 18.23 & 274.36 & 39.60 & 85.57 \\
\hline 7 & 12.00 & 2.00 & 9.20 & 19.22 & 5.38 & 72.00 & 1163.73 & 45.16 & 96.12 \\
\hline 8 & 13.98 & 2.00 & 10.02 & 7.83 & 4.63 & 40.82 & 204.84 & 39.52 & 80.71 \\
\hline
\end{tabular}

From the Table 2 we can see that maximum stress value was $19.22 \mathrm{MPa}$ and the minimum stress value was $4.58 \mathrm{MPa}$, their quantitative difference was 14.64 MPa under the flexible yield support form; while the maximum stress was $7.52 \mathrm{MPa}$, the minimum value was $1.53 \mathrm{MPa}$, the difference between them was 4.99 MPa by rigid-flexible integrated support with energy absorbing form. The stress under rigid-flexible integrated support with energy absorbing at different location were smaller than the flexible yield support, where the maximum stress descended $72 \%$. Furthermore, the maximum energy acted on the support was $1163.73 \mathrm{~kJ} / \mathrm{m} 3$ and the minimum value was $70.54 \mathrm{~kJ} / \mathrm{m} 3$, the maximum energy was 16.5 times than the minimum value under the flexible yield support. When the maximum energy became $45.16 \mathrm{~kJ} / \mathrm{m} 3$ and the minimum value was $28.20 \mathrm{~kJ} / \mathrm{m} 3$, the maximum to the minimum was 1.6 times with the rigid-flexible integrated support with energy absorbing. Thus it can be seen that the energy acted on the support unit 
areas was significantly reduced, the largest amplitude reduction was $96.58 \%$ and the smallest decreased degree was $60.02 \%$, the energy distribution trend to be homogenization.

The results of numerical simulation shows that the rigid-flexible integrated support with energy absorbing can not only absorb the stress and energy produced by impact load, but also can make energy evenly distributed to different positions of the supporting structure, which can reduce or even avoid the destruction of the supporting structure by impact loading.

\section{Field Application}

In order to exam whether the rigid-flexible integrated support with energy absorbing can prevent rock burst, the field test was made in the 25110 workface in Yuejin coal mine. The depth of primary mineable coal bed in Yuejin coal mine was even $1000 \mathrm{~m}$ and the coal and roof has weak bump proneness. Rock burst occurred many times in the mining workface during the past few years and the frequency and intensity with the depth has been increasing. There were 39 times rock burst happened since the 25090 workface first begun in 2006 , the cumulative damaged roadway was more than $2500 \mathrm{~m}$. The support form for rock burst prevention improved gradually in Yuejin coal mine. The flexible yield support form composed by anchor, metal mesh, steel strip beam, cable, O-shed with 36Mn U-shaped steel in 23130 workface, the schematic diagram as shown in Figure 6.

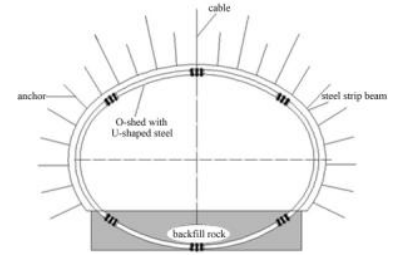

Fig. 6 Schematic Diagram of Flexible Yield Support in Yuejin Coal Mine

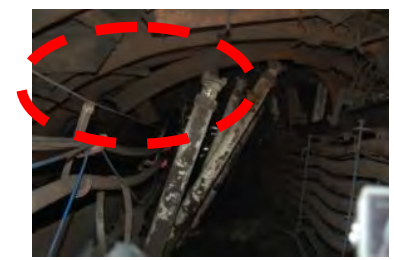

Fig. 7 Damage Picture of Flexible Yield Support at 23110 Workface in Yuejin Coal Mine

With the flexible yield support, there were 14 times rock burst occurred during the 23130 workface mining which gives rise to effective prevention. The most seriously rock burst happened in the 9th of November 2009 and 1st of March 2011, and some parts of support form were damaged, such as the metal mesh broken, the beam of the $\mathrm{O}$-shed deformed and ruptured, the most of single prop before the workface tilted and the support was invalid, as shown in Figure 7. Therefore, the flexible yield support has some parts need to be improved to fit in with the needs of rock burst prevention.

By steady effort and practice, the rigid-flexible integrated support with energy absorbing was invented, it has the characteristics of fully-closed, high intensity, yieldable, constant resistance and energy absorbing. There was a three-level support in this system. The first level composed by high strength pre-stressed anchorage thread steel resin bolt, small aperture pre-stressed resin anchorage cable, cross steel band and the steel mesh. The second support level was the O-shed with high strength $36 \mathrm{U}$-shaped steel, which is the fully enclosed support. The third level was the monolithic power hydraulic yieldable door-maintaining. The effect drawing of this support is as shown in Figure 8.

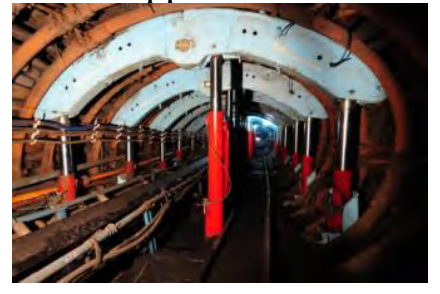

Fig. 8 The Effect Drawing of Rigid-flexible Integrated Support with Energy Absorbing in Yuejin Coal Mine

The 25110 working face occurred an rock burst with the released energy was $9 \times 107 \mathrm{~J}$ and the magnitude 3.2 when 12 workers were maintaining the machines in 1st of March 2011. Thanks to the protection of the rigid-flexible integrated support with energy absorbing, there were no people casualties. The blast wave caused slight damage of $200 \mathrm{~m}$ roadway and some equipment. After simple cleaning and repairing, the workface resumed production. 
Since this support form was used in the roadway of 25110 workface, the rock burst was basically controlled and achieved the purpose of no casualties and no effect produce when rock burst happened.

\section{Summary}

According to the failure characteristics of roadway in rock burst mine, the rigid-flexible integrated support with energy absorbing was put forward and its prevention mechanism was analyzed.

Compare to the flexible yield support, this new support form can not only absorb stress and energy effectively, but also make the energy distribution trend to be homogenization. The largest amplitude reduction was $96.58 \%$ and the smallest decreased degree was $60.02 \%$, the energy distribution trends to be homogenization.

With this support form, the frequency of rock burst concurrency and intensity were both declined. The extent of damage to roadway, machines and workers were effectively decreased in several seriously rock burst with high energy released in Yuejin coal mine, which achieve the purpose of no casualties and no effect produce when rock burst happens.

\section{Acknowledgement}

The authors wish to acknowledge the financial support and permission to publish this paper by the China Coal Research Institute (CCRI) and the support by the State Key Development Program for Basic Research of China (Grant No. 2010CB226806), the National Natural Science Foundation of China (Grant No. 51174112 and Grant No. 51174272). These supports are gratefully acknowledged..

\section{References}

[1]M.S.Gao; L.M.Dou and N.Zhang. 2008. Strong-soft-strong mechanical model for controlling roadway surrounding rock subjected to rock burst and its application.. Rock \& Soil Mechanics, v.29, p.359-365.

[2]X.W.Feng; Z.W.Zhang and R.P.Cao. 2001. Surrounding rock controlling technique of rigid-yielding secondary coupling supporting in deep coal gate. Ground Pressure \& Strata Control, v.4, p.18-20.

[3]S.B.Chen; Q.F.Yan and X.F.Zhang. 2000. Application of bolt support technology to pressure bump seam roadway. Coal Seience \& Technology, v.7, p.22-25.

[4]Y.S.Pan; X.F.Lv and Z.H.Li. 2011. The model of energy-absorbing coupling support and its application in rock burst roadway. J. Mining \& Safety Engineering, v.1, p.6-11.

[5]Y.X.Zhao; Y.D.Jiang and S.P.Tian. 2010. Investigation on the characteristics of energy dissipation in the preparation process of coal bumps. J. China Coal Society, v.35, p.1979-1984. 